\title{
Evaluation of local stress-based fatigue strength assessment methods for welded structures subjected to axial and bending loading
}

\author{
Jinchao Zhu ${ }^{1}$, Imad Barsoum², Zuheir Barsoum ${ }^{1}$, and Mansoor Khurshid ${ }^{1}$ \\ ${ }^{1}$ Kungliga Tekniska Hogskolan \\ ${ }^{2}$ Department of Mechanical Engineering Khalifa University PO Box 2533 Abu Dhabi UAE
}

February 11, 2022

\begin{abstract}
The current study aims to find suitable fatigue assessment methods for welded structures (cover plates and T-joints) subjected to axial and bending loading. For this purpose, the Hot Spot Stress method (HSS), 1-mm stress (OM) method, Theory of Critical Distances (TCD) method, Stress Averaging (SA) method, and Effective Notch Stress (ENS) method are evaluated in terms of accuracy and reliability. The evaluation is based on fatigue test data extracted from the literature and fatigue testing carried out in the current study; cover plate joints subjected to axial loading and T-joints subjected to bending. The notch stress methods have higher estimation accuracy for the cover plate joints subjected to axial loading than the structural stress methods. It is found that the SA method can be used to assess the fatigue strength of cover plate joints with good accuracy and low scatter, followed by the ENS method. The fatigue strength assessment of T-joints subjected to bending using the HSS method, TCD method, SA method, and ENS method and corresponding FAT class is conservative, whilst the accuracy is low. Fatigue design curves applicable for T-joints under bending are introduced and described, which can be used in the TCD method, SA method, and ENS method.
\end{abstract}

\section{Hosted file}

Manuscript submit.docx available at https://authorea.com/users/459946/articles/556047evaluation-of-local-stress-based-fatigue-strength-assessment-methods-for-welded-

structures-subjected-to-axial-and-bending-loading 